\title{
The First Year of Life
}

\section{CONTRAINDICATIONS TO IMMUNISATION}

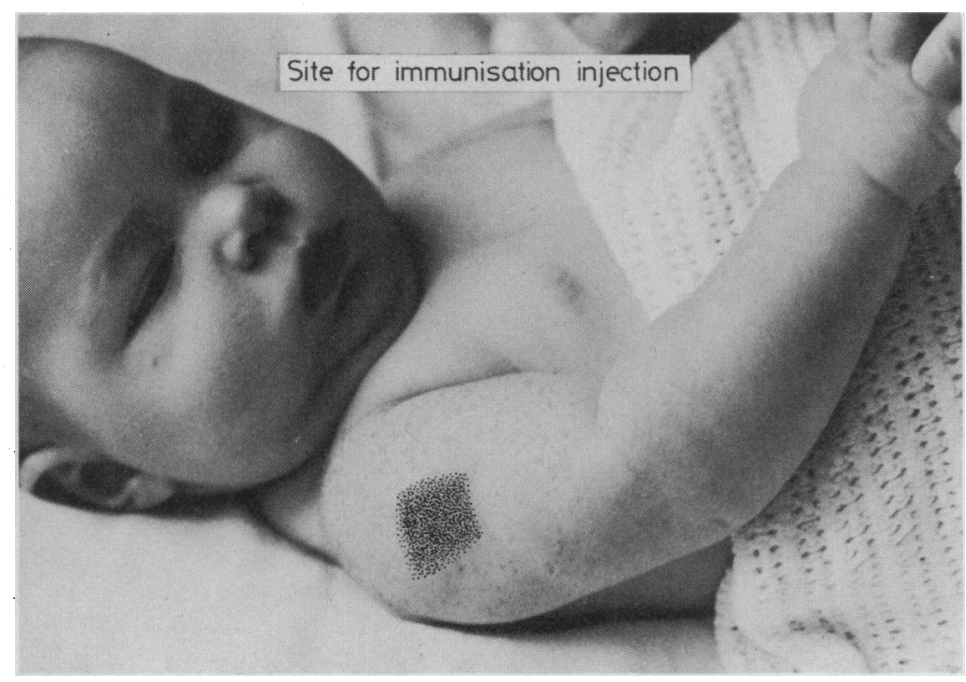

Immunisation should be postponed if an infant has any acute febrile illness or diarrhoea, but a common cold or "snuffles" is not a contraindication.

\section{Toxoids and killed vaccines}

\section{Whooping cough}

\section{Tetanus}

Diphtheria

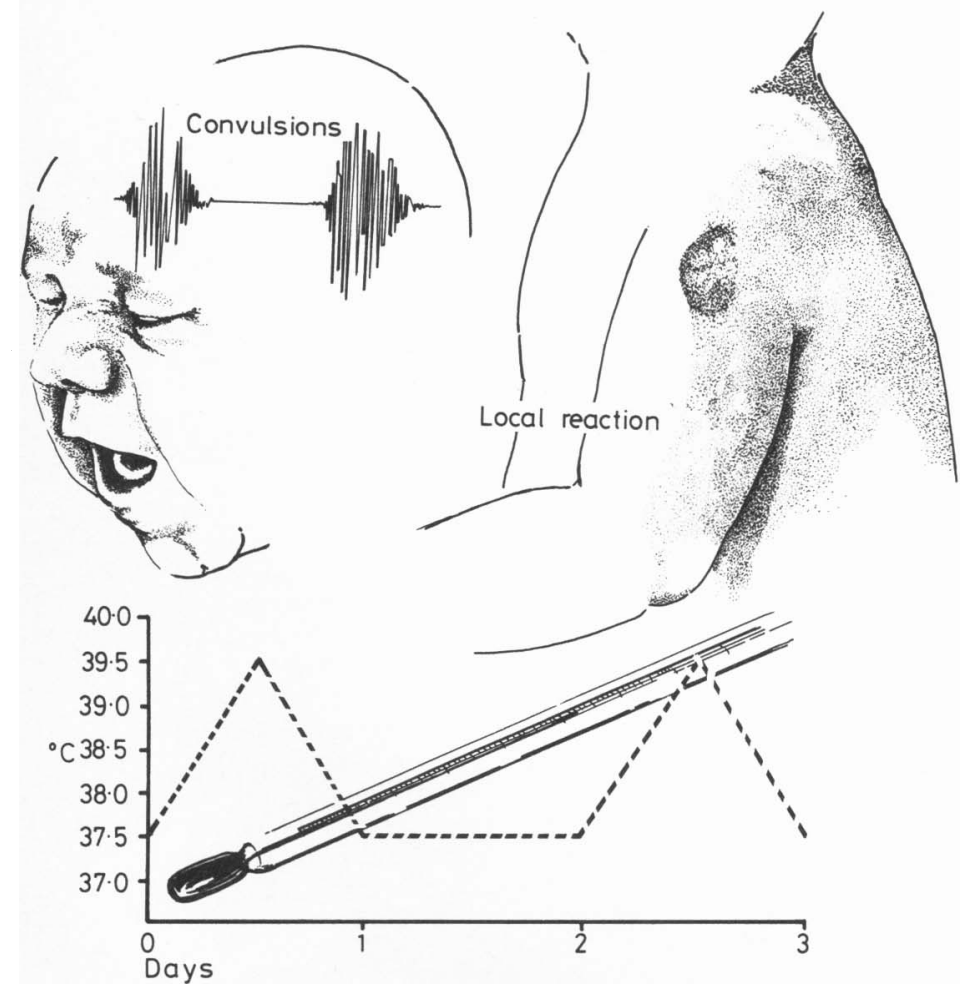

Contraindications to whooping cough vaccine are: fits or abnormal cerebral signs in the neonatal period, neurological abnormalities, developmental delay, and a family history of epilepsy or other diseases of the central nervous system. A general or local reaction to a preceding dose suggests that the vaccine should be avoided. A family or personal history of allergy is not a contraindication.

Acute infection is a contraindication to routine tetanus immunisation, though not in the presence of a tetanus-prone wound. When a child has suffered from a severe local reaction to a previous dose of adsorbed vaccine it may be preferable to administer $0.1 \mathrm{ml}$ of tetanus vaccine in simple solution intradermally.

Apart from acute infection there are no contraindications to immunisation with diphtheria vaccine. 


\section{Live vaccines}

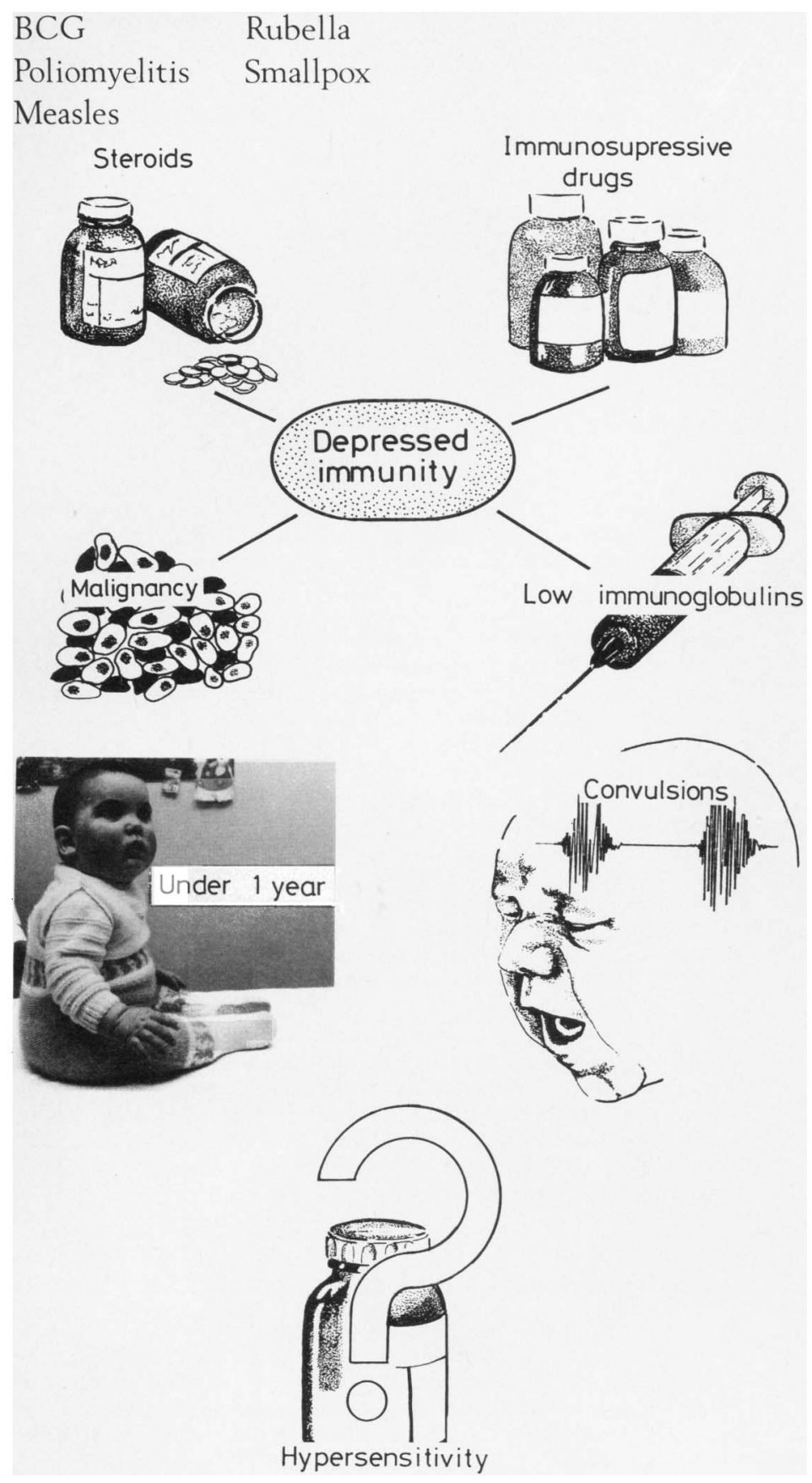

Live vaccines include BCG, poliomyelitis, measles, rubella, and smallpox vaccines, and they have many contraindications in common: they should not be given to infants with any immunological abnormality, including a low plasma IgG concentration; those with malignant diseases; or those receiving corticosteroids or immunosuppressive treatment.

Measles and rubella vaccines should not be given to infants aged under 1 year. They should also not be given within the incubation period to those who have been exposed to an infectious disease.

Rubella vaccine should not be given to children with known thrombocytopenia or a personal or parental history of fits. It should also not be given to children who are hypersensitive to neomycin.

Infants with the following conditions should not be given measles vaccine unless human normal immunoglobulin $(1.3 \mathrm{mg} / \mathrm{kg}$ body weight) with a specific content of measles antibody is given simultaneously at a different site: $(a)$ a history of convulsions; (b) parental history of epilepsy (non-traumatic); (c) chronic disease of the heart or lungs; $(d)$ serious failure to thrive. In the first three groups immunisation could be delayed until after the second birthday.

Smallpox vaccine is not now used routinely in the United Kingdom. It should not be given to infants with eczema or a history of it, and after vaccination infants must be kept from contact with anyone with eczema for 21 days.

BCG should also not be given to infants with chronic skin conditions such as eczema.

Oral poliomyelitis vaccine is contraindicated in children hypersensitive to penicillin, streptomycin, or neomycin.

Dr H B VALMAN, MD, FRCP, is consultant paediatrician, Northwick Park Hospital and Clinical Research Centre, Harrow.

\section{Schemes for immunisation}

\begin{tabular}{|c|c|}
\hline 3 months. & $\begin{array}{l}\text { Diptheria-tetanus-pertussis, } \\
\text { oral poliovaccine }\end{array}$ \\
\hline 5 months. & $\begin{array}{l}\text { Diptheria-tetanus-pertussis, } \\
\text { oral poliovaccine }\end{array}$ \\
\hline 9 months. & $\begin{array}{l}\text { Diptheria - tetanus - pertussis, } \\
\text { oral poliovaccine }\end{array}$ \\
\hline 13 months. & Measles \\
\hline $41 / 2$ years. & $\begin{array}{l}\text { Diptheria-tetanus-pertussis, } \\
\text { oral poliovaccine }\end{array}$ \\
\hline 13 years & Rubella \\
\hline 15 years & $\begin{array}{l}\text { Tetanus } \\
\text { optional: oral poliovaccine }\end{array}$ \\
\hline
\end{tabular}

Each district has its own policy for the timing of immunisations. The main difference is whether the first triple vaccine injection is given at three months or later. At least three weeks must elapse between immunisation with different live vaccines.

BCG vaccination is offered in the first week of life to children with families at risk and at 5 or 13 years depending on the local incidence of tuberculosis. 